УДК 339.9 .01

ББК 65.011

ВЛИЯНИЕ ИНТЕЛЛЕКТУАЛЬНОГО РЕСУРСА НА ЭКОНОМИЧЕСКОЕ РАЗВИТИЕ

\author{
Д. В. КУКАРЕКО \\ kukareka@bsu.by \\ аспирант, преподаватель экономического факультета \\ Белорусский государственный факультет \\ Минск, Республика Беларусь
}

В данной статье исследуется вопрос об изменении центральной роли ресурсов, влияющих на экономическое развитие современного общества. Постиндустриальное информационное пространство и экономика, основанная на знаниях, диктуют новые требования к институциональной структуре и взгляду на иенности и основы благосостояния страны. В связи с необходимостью повышения качества жизни населения на основе роста конкурентоспособности экономики, привлечения инвестиций и инновачионного развития, государственная политика должна строится с учетом преимущественного развития информационного сектора экономики, как доминирующего для возобновления экономического роста страны и выхода из кризиса.

Ключевые слова: постиндустриальное общество, инновации, интеллектуальный ресурс, интеллектуальный капитал, человеческий капитал

\title{
IMPACT OF INTELLECTUAL RESOURCES ON THE ECONOMIC DEVELOPMENT
}

\author{
D. V. KUKAREKO \\ Post-graduate, lecturer of economic faculty \\ Belarusian State University \\ Minsk, Republic of Belarus
}

This article deals with the change in the leading role of resources that influence current economic development in the world. Postindustrial informational area and knowledgebased economy require newly formed institutional infrastructure and fresh view on the values and basis of the countries' wealth. According to the necessity of improving the quality of life based on economic competitiveness ability, attracting investments and innovative development, economic policy should be lead adjusted for the leading role of informational industries that are able to renew countries' economic growth and overcome crisis.

Key words: postindustrial society, innovation, intellectual resource, intellectual capital, human capital

\section{ВВЕДЕНИЕ}

Современное общество вошло в эпоху постиндустриального информационного пространства, в мире господствует пятый технологический уклад, создаются предпосылки для перехода к шестому технологическому укладу, закладываются основы антропогенного общества. На смену индустриальному обществу с его воспроизводимыми и ограниченными товарами приходят качественно новые всеобщие и одновременно уникальные. Ценностью и основой благосостояния и экономического роста становится интеллектуальный ресурс, который включает в себя информацию, знания, любую не- 
материальную составляющую. На первый план выдвигается не собственность на средства производства, а человеческий капитал и инвестиции в него.

Быстрое повышение значимости сферы интеллектуальных ресурсов в мировых процессах развития происходит в контексте ускорения глобализации мировой экономики, связанной, в том числе, и с выходом мировых технологий на новый качественный уровень. Именно инновации, порождаемые знаниями, составляют основу глобальной экономики. Одной из важнейших черт экономики, основанной на знаниях, является нелинейность процесса развития: оно состоит из взлетов и падений, причем направление перемен зачастую сложно предвидеть.

Переход к пятому технологическому укладу начался в развитых странах с 70-х годов XX столетия. Поэтому проблематика использования интеллектуального ресурса активно разрабатывается на протяжении порядка 50 лет. Она находит отражение в трудах П. Друкера, К. Колина, Ф. Махлупа, Т. Умесао, Дж. Стиглера, Дж. Стиглица, Т. Стюарта, Д. Белла, Н. Негодаева, М. Пората, М. Маклюэна, Ф. Тейлора.

Различные точки зрения на инновации отражены в трудах Г. Менша, Ю. Яковца, Н. Кондратьева, С. Кузнеца. Особая роль отводится образованию как фактору инновационного развития экономики, а также взаимосвязи научных, экономических и инновационных циклов. Важное место в инновационной активности отводится субъекту - автору идеи, который первым ощущает необходимость инноваций и перемен в той или иной сфере общества.

\section{РЕЗУЛЬТАТЫ И ИХ ОБСУЖДЕНИЕ}

Интеллектуальные ресурсы стали вызывать пристальный интерес в связи с переходом развитых стран к постиндустриальному обществу. Индустриальное производство, часто приравненное к термину «экономика», уступает место новой экономике, основанной на знаниях (knowledge-based economy)*. В информационном обществе информация и знания рассматриваются в качестве важнейшего фактора инновационного развития. К примеру, Европейский саммит 2000 года в Лиссабоне был сконцентрирован на «соглашении о новой стратегической цели Европейского союза, опирающейся на увеличении занятости населения, проведении экономических реформ, социального единства как части экономики, основанной на знаниях» [1].

Главная цель развития Республики Беларусь на 2016 - 2020 годы - повышение качества жизни населения на основе роста конкурентоспособности экономики, привлечения инвестиций и инновационного развития [2]. Также указывается, что необходимо комплексное развитие национальной инновационной системы, что включает стимулирование экономики и инвестиционной активности, повышение роли фундаментальной науки, упрощение условий коммерциализации результатов научно-технической деятельности, а также укрепление инновационной инфраструктуры индустриальными площадками для создания высокотехнологичных производств.

Механизмы перехода к новому типу организации общества неразрывно связаны с интенсивной кристаллизацией научно-инновационной среды. Именно поэтому понятие «инновации» является ключевым в рассмотрении вопросов трансформации индустриального общества в постиндустриальное и информационное. Важнейшее же значение здесь принадлежит, естественно, науке [3].

* Существуют различные вариации этого термина - «knowledge society», «knowledgeable society», «knowledge-value society». 
Шестой технологический уклад характеризуется нацеленностью на развитие и применение наукоёмких, или «высоких технологий». Это био- и нанотехнологии, генная инженерия, мембранные и квантовые технологии, фотоника, микромеханика, термоядерная энергетика - синтез достижений на этих направлениях должен привести к созданию, например, квантового компьютера, искусственного интеллекта и в конечном счёте обеспечить выход на принципиально новый уровень в системах управления государством, обществом, экономикой [4].

В соответствии с цивилизационным подходом и методом общественных формаций - как индустриальное общество, основной ценностью которого выступал товар, сменилось постиндустриальным (информационным) обществом, основной ценностью которого являются услуги (в том числе информационные), так и антропогенное общество придёт на смену постиндустриальному.

Понятие «информационная экономика» было впервые использовано американским учёным М. Поратом в середине 70-х годов XX века, однако данный термин получил широкое признание только после присуждения в 1982 году Нобелевской премии Дж. Стиглеру, который констатировал, что «информация - это недооцененный ресурс, а знание - власть» [5]. Другой лауреат Нобелевской премии 2001 года Дж. Стиглиц отметил: «В рамках информационной экономики происходит фундаментальное изменение доминирующей экономической парадигмы» [6].

Экономика, основанная на знаниях, или экономика постиндустриального общества, имеет ряд отличительных признаков. Это отделяет ее от предшествующих общественных формаций.

Во-первых, именно знание является основой для формирования стоимости продукта. Увеличивается наукоемкость произведенной продукции, представленной на рынок интеллектуальных товаров и услуг. Именно производство такой продукции повышает производительность труда. К примеру, в Парке высоких технологий в 2006 году производительность труда была сопоставима со средней по стране. В последующие годы она росла неуклонно, что характерно, показывая стабильность прироста в посткризисный 2009 год [7]. В итоге в 2014 году величина производительности труда в Парке высоких технологий в 1,9 раз превысила производительность труда в экономике и составила \$32.451. В ответ на снижение производительности труда в экономике 26 января 2016 г. издан Указ № 26 о внесении изменений в Директиву Президента Республики Беларусь от 14 июня 2007 г. № 3 «Экономия и бережливость - главные факторы экономической безопасности государства», где указана необходимость обеспечить кардинальное изменение качества управления промышленным комплексом страны в целях поступательного приближения к европейскому уровню производительности труда [8].

Тенденция формирования большей части стоимости товара интеллектуальной составляющей пришла и в производство материальных благ - так до 70\% стоимости современного легкового автомобиля образуют дизайн, электроника и другие интеллектуальные компоненты. Все более наукоемкими становятся такие «доиндустриальные» отрасли, как добыча полезных ископаемых, производство сельскохозяйственных продуктов. По оценкам Т. Стюарта, научные разработки образуют 50\% стоимости нефти и 75\% стоимости зерна [9]. С ним согласен П. Друкер, который называет современное сельское хозяйство одной из наиболее наукоемких отраслей [10]. Это неудивительно при той роли, которую играют в современном сельском хозяйстве биотехнологии, генетика, вычислительная техника.

Во-вторых, все большее значение приобретает деятельность, связанная с производством, хранением, передачей и использованием знаний. В 2016 году продолжил набирать обороты такой сегмент как облачные услуги (хранение данных, обработка, 
инфраструктура и реклама). По прогнозам его прирост по итогам года составит $16 \%$, а объем - более 5\% объема рынка IT-услуг, что весьма внушительно. Майкрософт потратила 3 млрд. долл. за 2015-2016 гг. на расширение облачной инфраструктуры в Европе, чтобы потеснить своих главных конкурентов - Гугл и Амазон. А к примеру, Азиатский регион выбирает облачное хранение для данных в медицинском обслуживании, что помогает сократить бюджет в несколько раз и обеспечить быстрый и простой доступ к данным. Консалтинговая компания PricewaterhouseCoopers (PWC), проанализировав местные отраслевые рынки стран Юго-Восточной Азии, пришла к выводу, что они разрабатывают собственную модель цифровой медицины, которая выведет их здравоохранение из кризиса [12].

Особая же роль в производстве знаний принадлежит образованию, которое рассматривается как инвестиции в развитие человеческого капитала, от которого зависит качество и успех производства. Американские компании увеличили затраты на переподготовку своих работников на 34\% с 2010 по 2015 год, и общая цифра составила 70 млрд. долл. [12].

Третье - это доминирование работников, занятых производством, использованием и передачей информации и знаний в доминирующую группу. В начале 2016 года среднесписочная численность персонала в белорусских ИТ-компаниях составляла 24,8 тыс. человек. В то время как в машиностроении было занято 124,1 тыс. человек. А вот фонд оплаты труда в этих сегментах сравнялся. И хотя на данный момент в белорусских ИТ-компаниях работает менее $1 \%$ сотрудников от среднесписочной численности работников всех предприятий страны, доля ИТ-сектора в ФОТ выросла до 5\%.

В современной мировой экономике новые знания, воплощаемые в производстве, составляют до $85 \%$ прироста ВВП, что позволяет утверждать о прямой зависимости экономического роста от НТП и интеллектуализации основных факторов производства. Так, в информационной экономике информация становится не только основным фактором производства, но под влиянием информации происходят радикальные экономические трансформации других факторов (рисунок 1).

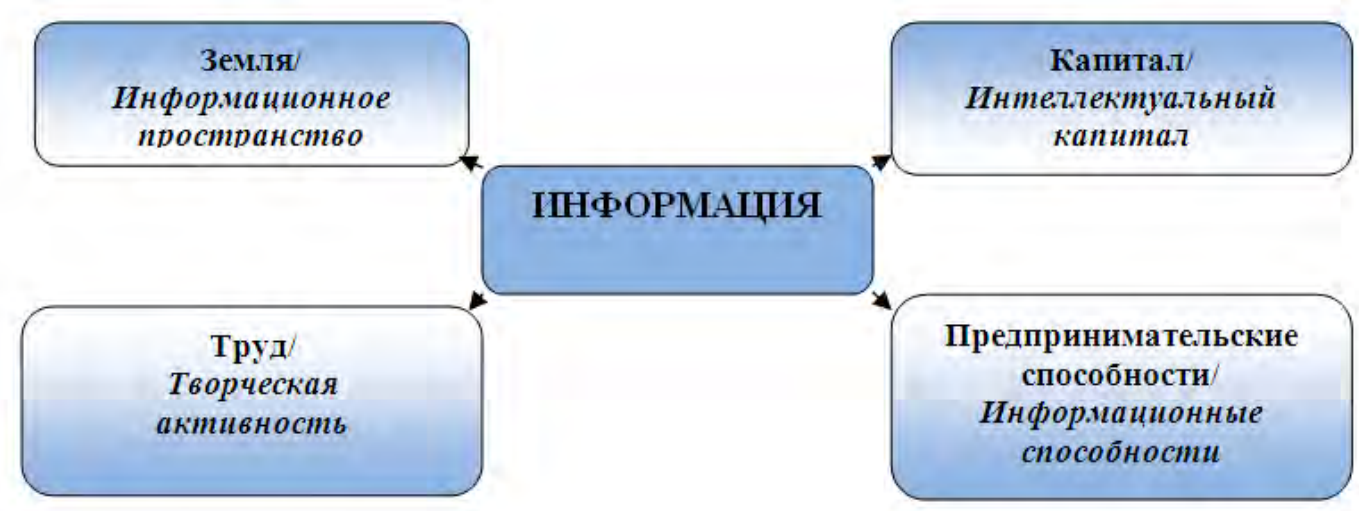

Рисунок 1 - Трансформации факторов производства в информационной экономике

В современной теории и методологии информационного общества наибольшее значение имеют два подхода:

технократический подход, когда акцентируется внимание на исследовании информационных и коммуникационных технологий, их качества, сложности применения и, как результата внедрения, осязаемости материального вклада в увеличение производительности труда. Использование ИКТ рассматривается в основном в сферах произ- 
водства, менеджмента и сбыта, при этом трудовые ресурсы исследуются исключительно как средство производства. Наиболее известные представители технократического подхода - М. Маклюэн, Ф. Тейлор, Э. Дагбаев и др.

гуманитарный подход, когда информационные и коммуникационные технологии не рассматриваются как центральный элемент экономической активности. Согласно данной концепции, функционирование производства и его эффективность зависят в первую очередь от уровня мотивации трудовых ресурсов, возможности создания динамичных исследовательских команд, развития творчества, что предполагает всестороннее изучение социально-личностных качеств работников. Яркими представителями этого подхода являются Р. Якобсон, К. Леви-Строс, В. Шрамм и др. [13]

Теория информационной экономики как теория общественного развития является мультипредметной наукой, находящейся на стыке экономики, социологии, информатики, математики, психологии и других наук. Поэтому для изучения информационной экономики необходим междисциплинарный метод исследования, основанный на синтезе научных знаний, выявление содержания и принципов функционирования столь сложной системы как информационная экономика, соединившая в себе достижения предыдущих экономических систем.

К анализу современной модели информационной социоэкономики необходимо применять системный институционально-эволюционный подход. В советской политэкономии научное знание рассматривалось как общественное благо, которое не может эффективно производиться частным сектором, в связи с чем обосновывалась монополия государственного регулирования научных исследований. В постсоветский период характер научных исследований и инноваций изменился в связи с необходимостью усиления конкурентных позиций в мировой экономике; инновации стали рассматриваться более комплексно как процесс взаимодействия различных субъектов инновационной системы (включая исследовательские организации, фирмы и государство), что обусловливает комплекс формальных и неформальных институтов страны. Методологической основой этого подхода становятся отдельные направления нового институционализма в экономической теории (о широком признании и востребованности нового институционализма свидетельствуют Нобелевские премии, полученные его представителями - Р. Коузом, Дж. Бьюкененом и Д. Нортом).

Рассмотрим ключевые особенности, характерные для информационной экономики, по сравнению с предыдущими стадиями экономического развития:

Согласно методологии маржинализма, ценность товаров/услуг определяется редкостью, а их излишнее производство приводит к снижению ценности. Так, ковры потеряли значительную часть ценностной значимости, когда их стали массово изготавливать на станках. В информационном секторе экономики ценность определяется избыточностью предложения и максимальным объёмом распространения - чем больше товаров/услуг продаётся в информационной сети, тем более ценным становится каждый из них. Данная закономерность опровергает методологию маржинализма. Согласно закону Р. Меткалфа [14], при увеличении в два раза количества пользователей ценность для каждого пользователя удваивается, при этом суммарная ценность сети подчиняется закономерности $n(n-1)$, где $n$ - количество пользователей. Например, для мобильной связи - чем больше субъектов (людей и организаций, которым можно позвонить) подключено к сети, тем больше ценность каждого телефона абонента. Возникает положительная обратная связь, когда все владельцы существующих телефонов заинтересованы в расширении сети и получают эффект (в том числе экономический например, снижение стоимости звонка) от такого расширения. Действие этого закона сейчас очень четко прослеживается на жизнеспособности социальных сетей, таких как 
Facebook, Вконтакте, Инстаграмм и им подобным, которые хотят повторить успех вышеназванных.

Рассматривая устройство постиндустриального общества и принципиально новое - информационного общества, мы видим, что постепенно господствующими в экономике становятся не ограниченные ресурсы (природа и человек), а новый тип «ресурсов» - продукты интеллектуального труда. Эти «ресурсы» неограниченны, неуничтожимы, они могут быть «потребляемы» сколь угодно широким кругом лиц и на протяжении сколь угодно продолжительного периода времени. И это такой пирог, который становится тем больше, чем шире круг едоков и чем активнее они его поедают (так Чайковский, «съев» творение Пушкина, создает свою оперу, и «пирог» искусства становится богаче) [15].

В информационной экономике действует принцип инверсионной себестоимости. Если в индустриальной экономике любое, даже незначительное, усовершенствование товара приводило к росту его цены, то в информационной среде существует тенденция снижения цен на качественные товары и услуги по прошествии определённого периода времени. Получение существенно более качественного товара за меньшие деньги возможно, если подождать с его покупкой. Например, компьютеры - один раз в полгода выходят новые, более качественные, комплектующие, а морально устаревшие резко (в 1,5-2 раза) снижаются в цене. Либо эта тенденция очень заметна на рынке смартфонов, в особенности таких ведущих марок как Apple Iphone и Samsung. Каждый год эти компании представляют на рынок флагманы - новые версии наиболее популярных моделей. И сразу же цена на предыдущую модель резко снижается. Однако здесь подключается еще и эффект Веблена с демонстративным потреблением, ведь актуальность предыдущей модели не снижается адекватно снижению цены, но иметь новый смартфон престижнее. Тем не менее необходимо отметить, что трансформация стоимости в информационной экономике пока происходит только на рынках информационных товаров, телекоммуникаций, компьютерной техники и электроники. Таким образом, принцип инверсионной себестоимости свидетельствует о падении стоимости товаров и услуг в сочетании с ростом их качества, в связи с чем фирмы информационной экономики вынуждены постоянно повышать качество продукции, расширять ассортимент и объём предлагаемых услуг, что приводит к ускорению всех экономических процессов (концентрации ресурсов, организации производства, получения прибыли/убытков и т. д.). В результате срок существования субъектов хозяйствования в информационной экономике, по некоторым подсчётам [16], в 3 раза меньше соответствующего срока в индустриальной экономике.

В индустриальной экономике такое снижение цен продукции в больших масштабах привело бы к банкротству. В информационной экономике действует принцип «сначала стать вездесущими». Компания Netscape, создававшая интернет-браузеры и обеспечивавшая их поддержку с 1994 г. по 2007 г., бесплатно предоставила 40 млн. копий своего программного продукта. Корпорация SUN бесплатно распространила язык программирования Java [17]. Продавая в последующем модернизированные и обновлённые версии информационного продукта и сервисное обслуживание к нему, фирмы получают возможность постоянно хорошо зарабатывать. Также ярким примером может быть поисковая система Google, которая до 2000 года завоевывала пользователей и совершенствовала поисковые инструменты, пользуясь инвестициями, а уже после запустила инструмент для заработка на рекламе, такой как Google AdWords.

Определяющей становится креативная деятельность, способность человека к общественно-полезной деятельности. И целью этой деятельности становится воспроизводство и расширенное воспроизводство интеллектуального капитала. Соответствен- 
но изменяется и субъект собственности. На смену рациональному homo economicus идет homo creator - субъект с иной системой ценностей, потребностей и мотивов. Термин креативный (творческий, созидательный) довольно часто употребляется при описании различных аспектов деятельности человека. Он соответствует созданию новой системы навыков, знаний и умений. Само состояние внешней среды, которое характеризуется непредсказуемостью, быстротой изменений и сложностью, требует гибкости и креативного, творческого подхода, который основывается на имеющихся знаниях и опыте.

Однако если получение и использование знаний как ресурса для экономического и технического прогресса не сопровождается институциональными изменениями, то приводит к несогласованности выбора, осуществляемого двумя группами менеджеров, имеющими несовпадающие интересы: производственниками и бюрократами. Цель производственников состоит в максимизации выпуска, тогда как цель бюрократов в минимизации удельного расхода информационного ресурса. Выход состоит в постоянном изменении социальной технологии по мере движения экономики по траектории роста.

В итоге актуальность приобрел вопрос об институциональных преобразованиях, которые способствуют экономическому росту в переходных и развивающихся экономиках. Вывод состоит в том, что росту способствуют определенные институты, которые и необходимо развивать в стране. Однако мнения расходятся по поводу того, какие же это должны быть институты. Проблема рассматривается такими исследователями как В. Полтерович [18] и В. Тамбовцев [19]. На основании этих исследований можно прийти к выводу, что значение имеет не только формирование институтов, которые станут основой роста, но и их последующее развитие и структурное изменение, согласованное с потребностями дальнейшего экономического роста.

Еще Саймон Кузнец на первое место из факторов, определяющих удачное применение накопленного опыта передовых стран, поставил достаточность стартового накопленного человеческого капитала. Высокий уровень и качество накопленного человеческого капитала необходимы для ускоренного осуществления институциональных реформ, трансформации государства, технологического обновления производств, рыночных преобразований экономики и т. д. Таким образом, человеческий капитал, по Кузнецу, является главной доминантой возможного стабильного роста экономик развивающихся стран. Существуют различные подходы к оценке человеческого капитала, и каждый из них подвергается критике. Доходы от использования человеческого капитала могут иметь денежную и неденежную форму. При обобщенной оценке человеческого капитала организации используются следующие подходы: затратный, доходный, экспертный, сравнительный.

У людей с высшим образованием запасов человеческого капитала больше, чем у людей с более низким уровнем образования. В Беларуси в 2014 году среди всех работников 29,4\% имели высшее образование, 22,5\% - среднее-специальное образование, $20,4 \%$ - профессионально-техническое, остальные $27,7 \%$ - общее среднее и базовое (рисунок 2). 


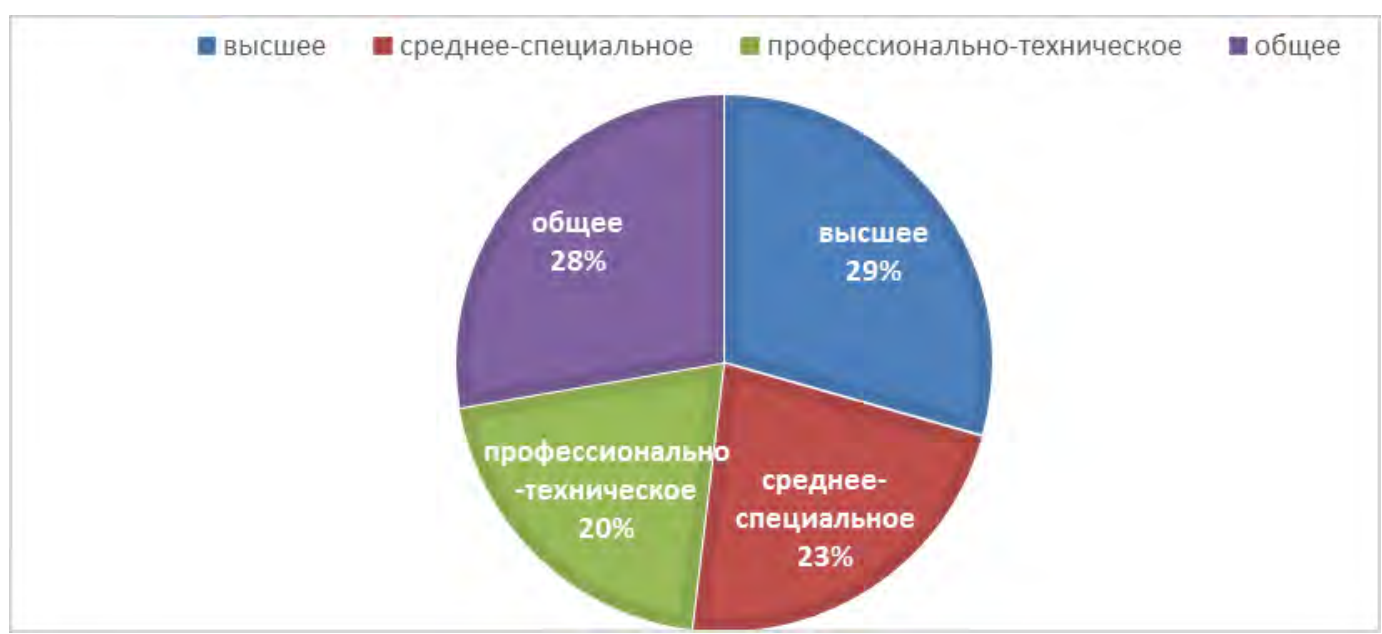

Рисунок 2 - Уровень образования работников в Республике Беларусь на конец 2014 года

Максимальная концентрация работников с высшим образованием в таких видах экономической деятельности как финансовая деятельность $(68,6 \%)$ из числа всех работников в этой сфере, государственное управление $(68,2 \%)$, операции с недвижимым имуществом (до 2016 года включает услуги в сфере информационных технологий, которые в новой методологии, начиная с отчетов за январь-март 2016 г. эти услуги будут отражены в секции «Информация и связь») $(55,4 \%)$ и образование $(54,1 \%)$. Номинальная начисленная средняя заработная плата в январе 2016 г. в финансовой деятельности составила 11,8 млн. неденоминированных белорусских рублей, в сфере информационных технологий - 35,5 млн., в образовании - 4,9 млн. А вот количество персонала, занимающегося исследованиями и разработками за 15 лет, сократилось на $20 \%$, причем из них количество вспомогательного персонала возросло с $30 \%$ до $40 \%$ от общего числа. Трудовые же ресурсы в общем за тоже время сократились на 4,5\% [20].

Индекс развития человеческого капитала (Human Capital Index 2015), публикуемый аналитической группой Всемирного экономического форума, оценивает уровень образования, здоровье, трудоустройство и инфраструктуру (правовая защита и социальная мобильность). Беларусь не оценивается рейтингом, однако для нас будут характерны все черты, присущие нашим соседям по восточноевропейскому региону: мы выигрываем в силу высокообразованного старшего поколения, получившего образование во время жёсткого государственного регулирования советской школы, однако проигрываем по вовлеченности трудовых ресурсов в производственный процесс и производительности труда. В том числе имеем сравнительно низкую ожидаемую продолжительность жизни населения. Наши страны-соседи занимают места с 26 по 30 как страны с высоким уровнем человеческого капитала.

Индекс человеческого развития (Human Development Index), публикуемый Программой развития Организации Объединённых Наций, представляет собой оценку человеческого потенциала на макроуровне - уровне общества стран. Беларусь в рейтинге 2015 г. (за 2014 г.) заняла 50 позицию и возглавила группу стран с высоким уровнем ИЧР. В рейтинге оцениваются 3 группы показателей: здоровье и долголетие, продолжительность образования и уровень жизни. Эти три измерения стандартизируются в виде числовых значений от 0 до 1, среднее геометрическое которых представляет собой совокупный показатель ИЧР в диапазоне от 0 до 1. Числовой показатель Беларуси составил 0,798, а самый высокий у Норвегии - 0,944. 


\section{ВЫВОДЫ}

Из-за относительной бедности Республики Беларусь полезными ископаемыми и энергоносителями появляется жизненная необходимость развивать интеллектуальные ресурсы современного общества, сделав их основой новой информационноантропогенной эволюции. Поскольку Республика Беларусь также ограничена в ресурcax, которые можно было бы направить на государственную поддержку инноваций, определение небольшого перечня наиболее востребованных технологий представляется весьма актуальным. Однако страна обладает главным ресурсом, который при условии грамотного государственного управления может обеспечить быстрый переход экономики на качественно новый научно-технологический уровень: человеческим капиталом и интеллектуальным потенциалом белорусских ученых, изобретателей и рационализаторов, являющихся авторами инноваций. И здесь решающая роль отводится внедрению научных результатов, получению прибыли от их продажи. Экономический рост возможен только за счет активизации инновационной деятельности, а значит, коммерческая выгода является одной из ключевых задач любого субъекта хозяйствования, в том числе и научного учреждения.

В наследство от советского времени нам достался высокий уровень образованности населения и сильная школа. Образование как фактор инновационного развития, с одной стороны предоставляет доступ к знаниям и навыкам всем заинтересованным лицам, связанным с процессом инноваций и экономическим ростом, а с другой стороны стимулирует креативность и воображение, что упрощает процесс интеграции инноваций и реальной экономики. Когда экономика приобретает черты «экономики знаний», главным изменением в ее свойствах является сращивание, интеграция науки с фирмами и государства, появление новой, особой роли, ранее ей не свойственной. Если в индустриальной экономике основой конкурентного преимущества является доступ к дешевому сырью, дешевая рабочая сила и оборотный капитал, снижение издержек через эффект масштаба, то в экономике, основанной на знаниях, основой конкурентного преимущества являются скорость получения новых знаний, скорость инноваций, интеграция, создание новых предприятий, венчурные стратегии и трудовые ресурсы. Ключевую роль начинают играть сети или системы, которые могут эффективно распространять знания и информацию, а наука уже не является автономно функционирующей отраслью - она встроена в систему производства и диффузии знаний.

\section{СПИСОК ИСПОЛЬЗОВАННЫХ ИСТОЧНИКОВ}

1. Итоги Европейского саммита в Лиссабоне 23-24 марта 2000 [Электронный pecypc]. - Режим доступа: http://www.europarl.europa.eu/summits/lis1_en.htmc - Дата доступа: 08.01.2017.

2. Проект программы социально-экономического развития Республики Беларусь на 2016 - 2020 годы. [Электронный ресурс] - Режим доступа: http://www.president.gov. by/ru/sobranie/ - Дата доступа: 12.01.2017.

3. Лазаревич, А. А. Инновационная стратегия постиндустриального общества/ Мировоззренческие и философско-методологические основания инновационного развития современного общества: Беларусь, регион, мир: материалы междунар. науч. конф., г. Минск, 5 - 6 ноября 2008 г;; Ин-т философии НАН Беларуси. - Минск: Право и экономика, 2008.

4. Каблов Е. Шестой технологический уклад/ Наука и жизнь. - 2010 - № 4 
5. Stigler, G. The Economics of Information // Journal of Political Economy. - 1961. - № 3. - P. 213-225.

6. Stiglitz, J. Information and the Change in the Paradigm in Economics // American Economics Review. - 2002. - Vol. 92 - № 3. - P. 460. 81.

7. Серпикова А. В. Анализ деятельности и развития парка высоких технологий в Республике Беларусь. [Электронный ресурс]. - Режим доступа: http://elib.bsu.by/bit stream/123456789/150989/1/406-409.pdf - Дата доступа: 09.02.2017.

8. Указ № 26 от 26 января 2016 г. О внесении изменений и дополнений в Директиву Президента Республики Беларусь № 3. [Электронный ресурс]. - Режим доступа: http://president.gov.by/ru/official_documents_ru/view/ukaz-26-ot-26-janvarja-2016-g12976/ - Дата доступа: 11.02.2017.

9. Stewart, T. A. Intellectual Capital. The New Wealth of Organizations. New York: Currency Doubleday, 1997.

10. Друкер, П. Задачи менеджмента в XXI веке. - М.: «Вильямс», 2007.

11. Облачные технологии и открытый код спасут медицину развивающихся стран от краха [Электронный ресурс]. - Режим доступа: http://corp.cnews.ru/ news/top/2016-09-02_oblachnye_tehnologii_i_otkrytyj_kod_spasut_meditsinu. - Дата доступа: 18.03 .2017$.

12. 2015 Training Industry Report USA [Электронный ресурс]. - Режим доступа: http://pubs.royle.com/display_article.php?id=2309323\&id_issue=278428 - Дата доступа: 15.02.2017.

13. Баранов, А. М. Информационная экономика как основа новой экономической системы: теоретико-методологический аспект: автореферат диссертации ... кандидата экономических наук: 08.00.01/ [Место защиты: Рос. гос. гуманитар. ун-т (РГГУ)]. Москва, 2010. - 176 с.: ил. РГБ ОД, 61 10-8/3012

14. Кулешов, А. Н. На пути к федеральной РКІ/ Журнал "Information Security/ Информационная безопасность" \#1+2, 2006. [Электронный ресурс]. - Режим доступа: http://www.itsec.ru/articles2/crypto/na_puti_k_federalnoi/na_puti_k_federalnoi_tab.html Дата доступа: 26.03.2017.

15. Бузгалин, А. В. Частная собственность устарела/ Журнал Отечественные записки. - 2004. - № 6 (21) C. 240.

16. Бугорский, В. Н. Сетевая экономика. - М.: Финансы и статистика, 2007. -

17. Михайлов, В. А. Место и роль новых информационных технологий в современном социально-экономическом развитии // Проблемы информационной экономики: сб.науч.тр. под ред. Р. М. Нижегородцева. - М. : ЛЕНАНД, 2006. - Вып. V. C. 44 .

18. Полтерович, В., Попов, В. Демократия, качество институтов и экономический рост. [Электронный ресурс]. - Режим доступа http://www.intelros.ru/pdf/prognosis/ 115-132_polterovich-popov.pdf - Дата доступа: 21.04.2017.

19. Тамбовцев, В. Л. Теории институциональных изменений. - М.: ИНФРА-М, 2010. - 154 c.

20. Труд и занятость в Республике Беларусь. Статистический сборник. Национальный статистический комитет Республики Беларусь, 2016. - 220 с. 


\section{REFERENCES}

1. Itogi Evropejskogo sammita $\mathrm{v}$ Lissabone 23-24 marta 2000 [EHlektronnyj resurs]. - Rezhim dostupa: http://www.europarl.europa.eu/summits/lis1_en.htms - Data dostupa: 08.01.2017.

2. Proekt programmy social'no-ehkonomicheskogo razvitiya Respubliki Bela-rus' na 2016 - 2020 gody. [EHlektronnyj resurs] - Rezhim dostupa: http://www.president.gov.by/ ru/sobranie/ - Data dostupa: 12.01.2017.

3. Lazarevich, A. A. Innovacionnaya strategiya postindustrial'nogo obshchestva/ Mirovozzrencheskie i filosofsko-metodologicheskie osnovaniya innovacionnogo raz-vitiya sovremennogo obshchestva: Belarus', region, mir: materialy mezhdunar. nauch. konf., g. Minsk, 5 - 6 noyabrya 2008 g.; In-t filosofii NAN Belarusi. - Minsk: Pravo i ehkonomika, 2008.

4. Kablov, E. SHestoj tekhnologicheskij uklad/ Nauka i zhizn'. - 2010 - №4

5. Stigler, G. The Economics of Information // Journal of Political Economy. - 1961. - № 3. - P. 213-225.

6. Stiglitz, J. Information and the Change in the Paradigm in Economics // American Economics Review. - 2002. - Vol. 92 - № 3. - P. 460. 81.

7. Serpikova, A. V. Analiz deyatel'nosti i razvitiya parka vysokih tekhnologij v Respublike Belarus'. [EHlektronnyj resurs]. - Rezhim dostupa: http://elib.bsu.by/bitstream/123456789/150989/1/406-409.pdf - Data dostupa: 09.02.2017.

8. Ukaz № 26 ot 26 yanvarya 2016 g. O vnesenii izmenenij i dopolnenij v Di-rektivu Prezidenta Respubliki Belarus' № 3. [EHlektronnyj resurs]. - Rezhim dostu-pa: http://president.gov.by/ru/official_documents_ru/view/ukaz-26-ot-26-janvarja-2016-g-12976/ - Data dostupa: 11.02.2017.

9. Stewart, T. A. Intellectual Capital. The New Wealth of Organizations. New York: Currency Doubleday, 1997.

10. Druker, P. Zadachi menedzhmenta v XXI veke. — M.: «Vil'yams», 2007.

11. Oblachnye tekhnologii i otkrytyj kod spasut medicinu razvivayushchihsya stran ot kraha [EHlektronnyj resurs]. - Rezhim dostupa: http://corp.cnews.ru/ news/top/2016-0902_oblachnye_tehnologii_i_otkrytyj_kod_spasut_meditsinu. - Data do-stupa: 18.03.2017.

12. 2015 Training Industry Report USA [EHlektronnyj resurs]. - Rezhim dostupa: http://pubs.royle.com/display_article.php?id $=2309323 \& i d$ issue $=278428$ - Data dostupa: 15.02.2017.

13. Baranov, A. M. Informacionnaya ehkonomika kak osnova novoj ehkonomicheskoj sistemy: teoretiko-metodologicheskij aspekt: avtoreferat dissertacii ... kan-didata ehkonomicheskih nauk: 08.00.01/ [Mesto zashchity: Ros. gos. gumanitar. un-t (RGGU)]. - Moskva, 2010. - 176 s.: il. RGB OD, 61 10-8/3012

14. Kuleshov, A. N. Na puti k federal'noj PKI/ ZHurnal "Information Security/ Informacionnaya bezopasnost"' \#1+2, 2006. [EHlektronnyj resurs]. - Rezhim dostupa: http://www.itsec.ru/articles2/crypto/na_puti_k_federalnoi/na_puti_k_federalnoi_tab.html Data dostupa: 26.03.2017.

15. Buzgalin, A. V. CHastnaya sobstvennost' ustarela/ Zhurnal «Otechestvennye zapiski». - 2004. - № 6 (23)

16. Bugorskij, V. N. Setevaya ehkonomika. - M.: Finansy i statistika, 2007. - S. 240.

17. Mihajlov, V. A. Mesto i rol' novyh informacionnyh tekhnologij v sovremennom social'no-ehkonomicheskom razvitii // Problemy informacionnoj ehkonomiki: sb.nauch.tr. pod red. R. M. Nizhegorodceva. - M. : LENAND, 2006. - Vyp. V. - S. 44. 
18. Polterovich, V., Popov, V. Demokratiya, kachestvo institutov i ehkonomiche-skij rost. [EHlektronnyj resurs]. - Rezhim dostupa http://www.intelros.ru/pdf/prognosis/115132_polterovich-popov.pdf - Data dostupa: 21.04.2017.

19. Tambovcev, V. L. Teorii institucional'nyh izmenenij. - M.: INFRA-M, 2010. $154 \mathrm{~s}$.

20. Trud i zanyatost' v Respublike Belarus'. Statisticheskij sbornik. Nacio-nal'nyj statisticheskij komitet Respubliki Belarus', 2016. - 220 c.

Статья поступила в редакцию 5 мая 2017 года. 